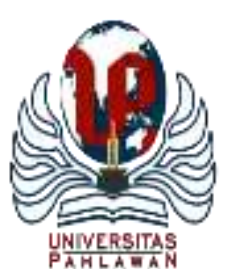

P $\overline{A H L A M A}$

\section{JURNAL BASICEDU}

Volume 5 Nomor 5 Tahun 2021 Halaman 3520 - 3530

Research \& Learning in Elementary Education https://jbasic.org/index.php/basicedu

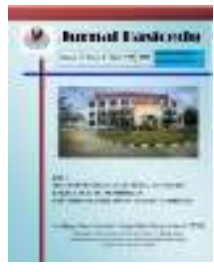

\title{
Pengembangan Mathlite untuk Meningkatkan Kemampuan Pemecahan Masalah Matematika di Sekolah Dasar
}

\author{
Yohana Setiawan $^{1 \bowtie}$, Aprilina Isabela Maharani ${ }^{2}$ \\ Pendidikan Guru Sekolah Dasar, Universitas Kristen Satya Wacana Salatiga, Indonesia ${ }^{1,2}$ \\ E-mail: yohana.setiawan05@gmail.com¹, aprilina.isabela@gmail.com²
}

\begin{abstract}
Abstrak
Penelitian ini bertujuan untuk mengetahui kelayakan Mathlite untuk meningkatkan kemampuan pemecahan masalah matematika SD. Penelitian ini menggunakan model Research and Development (R\&D). Dalam mengembangkan MathLite, penelitian ini menggunakan model Research and Development (R\&D) yang dikembangkan oleh Borg and Gall (1983). Dalam penelititian ini dilakukan tiga dari sepuluh tahapan penelitian yaitu, (1) penelitian dan studi pendahuluan, (2) perencanaan penelitian, dan (3) pengembangan produk awal. Teknik non tes yaitu kuesioner dengan empat skala kepada tiga validator ahli yaitu ahli media, ahli sastra anak, dan ahli materi matematika SD. Teknik analisis yang digunakan adalah teknik analisis deskriptif. Hasil validasi oleh Ahli Materi, Media, dan Sastra Anak menunjukkan bahwa MathLite seri Kerajaan Tudus layak digunakan untuk meningkatkan kemampuan pemecahan masalah matematika.
\end{abstract}

Kata Kunci: Matematika Siswa SD, MathLite, pemecahan masalah Matematika SD, Sastra anak.

\begin{abstract}
This study or research aims to determine the feasibility of Mathlite to improve elementary math problemsolving skills. This study uses the Research and Development $(R \& D)$ model. In the process of developing MathLite, this study uses the Research and Development $(R \& D)$ model that is developed by Borg and Gall (1983). In this research, three of the ten stages of research were used and done, which are, (1) preliminary research and studies, (2) research planning, and (3) initial product development. This non-test technique is a questionnaire with four scales to three expert validators, which includes media experts, children's literature experts, and elementary mathematicians. The analysis technique that is used is called descriptive analysis technique. The results of validation by Material, Media, and Children's Literature Experts shows that the Tudus Kingdom series MathLite is suitable to be used for improving mathematical problem solving skills.

Keywords: elementary math, Mathlite, elementary math problem solving, children's literature.
\end{abstract}

Copyright (c) 2021 Yohana Setiawan, Aprilina Isabela Maharani

Corresponding author :

Email : yohana.setiawan05@gmail.com

DOI : https://doi.org/10.31004/basicedu.v5i5.1375

ISSN 2580-3735 (Media Cetak)

ISSN 2580-1147 (Media Online) 
3521 Pengembangan Mathlite untuk Meningkatkan Kemampuan Pemecahan Masalah Matematika di Sekolah Dasar - Yohana Setiawan, Aprilina Isabela Maharani

DOI: https://doi.org/10.31004/basicedu.v5i5.1375

\section{PENDAHULUAN}

Progress in International Reading Literacy Study (PIRLS) adalah penilaian komparatif terhadap kemampuan membaca siswa khususnya kelas IV Sekolah Dasar (SD). PIRLS melakukan penilaian ini lima tahun sekali dimulai pada tahun 2001. Indonesia ikut berpatisipasi dalam PIRLS pada tahun 2006 dan 2011, namun pada tahun 2016 tidak ada data mengenai partisipasinya lagi. Percentage of 4th-grade students reaching the PIRLS international benchmarks in reading 2011 menunjukkan data bahwa dari 45 negara, Indonesia berada pada peringkat 4 yang posisi pertamanya ditempati oleh Singapura. Data itu menunjukkan bahwa kemampuan baca siswa kelas IV SD di Indonesia masih rendah (Ina V.S. Mullis, Michael O. Martin \& Drucker, 2012).

Upaya yang dilakukan pemerintah dalam hal ini Kemendikbud untuk menjadikan sekolah sebagai wadah yang anggotanya literat sepanjang hayat dituliskan dalam Desain Induk Gerakan Literasi Sekolah (Direktorat Jenderal Pendidikan Dasar \& Kebudayaan, 2016). GLS memiliki tujuan khusus yaitu menumbuhkembangkan budaya literasi di sekolah, meningkatkan kapasitas warga dan lingkungan sekolah agar literat, menjadikan sekolah sebagai taman belajar yang menyenangkan dan ramah anak agar warga sekolah mampu mengelola pengetahuan, dan menjaga keberlanjutan pembelajaran dengan menghadirkan beragam buku bacaan dan mewadahi berbagai strategi membaca. GLS senada dengan Peraturan Menteri Pendidikan dan Kebudayaan Nomor 23 Tahun 2015 tentang Penumbuhan Budi Pekerti yang mengajak peserta didik membaca buku selain buku pelajaran selama 15 menit sebelum pembelajaran berlangsung.

Keberhasilan dalam proses belajar mengajar tidak luput dari berbagai aspek di dalam lingkungan belajar seperti siswa, guru dan media pembelajaran. Pembelajaran yang efektif di dalam kelas dapat tercapai jika ketiga aspek tersebut dapat bekerja sama. Media pembelajaran yang interaktif memiliki potensi besar untuk merangsang siswa supaya dapat merespons positif materi pembelajaran yang disampaikan (Istiqlal, 2017). Salah satu media yang dapat merangsang respons siswa adalah adanya buku bacaan dalam pembelajaran. Menurut (AlHaddar \& Afdal, 2019), Kegiatan membaca buku bagi anak meruapakan suatu kegiatan yang sangat bermanfaat untuk mengasah dan menambah kecerdasan. Membaca dapat memperkaya anak dalam memahami berbagai kata yang ada di sekitarnya. Buku bacaan merupakan salah satu media yang efektif dalam pembelajaran.

Salah satu kendala yang saat ini ditemukan adalah belum adanya buku-buku cerita dengan "konsep matematika" yang mendukung program literasi. Ada banyak buku dongeng berkonsep hubungan social (IPS), bercerita tentang alam (IPA) dan buku-buku yang bertemakan religi. Berdasarkan hasil survey dan wawancara di tiga sekolah, yaitu SDN Kebonagung, SDN Tlogosih 2, dan SDN Sarimulyo 2 di Kabupaten Demak Jawa Tengah, semua sekolah tidak memiliki ketersediaan buku cerita anak dengan "konsep matematika" yang menunjang program literasi. Buku cerita anak juga belum dikembangkan dengan keterampilan pemecahn masalah. Hasil dari prasurvey ini didapati bahwa jumlah buku bermuatan matematika kelas 4 dibandingkan dengan jumlah keseluruhan buku di perpustakaan SDN Kebonagung 1 adalah 1,3\%, di SDN Tlogosih 2 adalah $1,8 \%$, dan di SDN Sarimulyo 2 adalah 2,9\%. Hal ini menunjukkan kurangnya dukungan literasi terhadap muatan pelajaran matematika di SD.

The National Council of Teachers of Mathematics (NCTM, 2000) dan (Setyaningsih, 2019) menentukan ada lima standar muatan dalam matematika yaitu bilangan dan operasi bilangan, aljabar, geometri, pengukuran, analisis data dan probabilitas. Sedangkan muatan matematika SD pada Peraturan Menteri Pendidikan dan Kebudayaan Nomor 21 Tahun 2016 tentang Standar Isi Pendidikan Dasar dan Menengah difokuskan pada materi bilangan, geometri dan statistika. Meskipun ada perbedaan muatan matematika, baik NCTM dan K13 menekankan pada keterampilan pemecahan masalah. NCTM menyatakan bahwa ada lima standar dalam berproses matematika yaitu problem solving, reasoning and proof, connections, 
3522 Pengembangan Mathlite untuk Meningkatkan Kemampuan Pemecahan Masalah Matematika di Sekolah Dasar - Yohana Setiawan, Aprilina Isabela Maharani

DOI: https://doi.org/10.31004/basicedu.v5i5.1375

communication, and representation. Senada dengan hal itu, ada Permendikbud no 22 tentang standar proses, pemecahan masalah diperlukan dalam mendukung kegiatan siswa pada ranah pengetahuan dan keterampilan.

MathLite adalah sebuah buku fiksi realistik anak yang dikembangkan dengan menggabungan muatan matematika dengan sastra anak. Genre fiksi realistik dekat dengan dunia (Brown, 1999), ((Mitchell, 2003) dan (Burhan Nurgiantoro, 2018). Sastra anak yang baik (Mitchell, 2003) dan (Burhan Nurgiantoro, 2018) mengandung unsur unsur seperti alur cerita (plot) yang tidak berbelit belit dan berkaitan dengan kehidupan sehari hari anak. Memiliki penokohan yang tidak terlalu banyak dan memiliki karakter yang jelas. Memiliki latar (setting) untuk mengetahui dimana dan kapan cerita ini berada. Diperlukan juag unsur tema dan moral agar pembaca dapat menjawab apa yang akan cerita itu sampaikan. Sastra anak juga memperhatikan gaya bahasa (style) supaya terjadi ikatan antara penulis dengan pembaca. Dampak emosional perlu dalam sastra anak agar apa yang dirasakan tokoh juga dirasakan oleh pembaca. Selain dampak emosional ada juga dampak imajinasi yaitu suatu kondisi yang membuat pembaca seolah olah menjadi tokoh dalam cerita. Unsur selanjutnya adalah unsur pikiran pengarang dan elemen ralistik yang mengajak pembaca mengetahui nilai kebenaran dalam suatu cerita yang disampaikan pengarang. Unsur lain yang tidak kalah penting adalah unsur ilustrasi yang memberi gambaran kepada pembaca. Ilustrasi yang baik biasanya berwarna dan jelas gambarnya. Unsur format mencakup tata letak ilustrasi, isi, ukuran huruf, jumlah lembar pada buku, tebal tipis buku, jenis kertas, warna, dan bentuk tulisan. Sebaiknya, satra anak tidak tebal dan tulisannya juga tidak kecil.

Pada MathLite seri Kerajaan Tudus ini, muatan matematikanya adalah berkaitan dengan geometri khususnya belajar tentang mengukur sudut pada kelas IV. Muatan ini dipilih untuk mendukung standar isi Matematika Kelas IV SD yaitu 3.12 Menjelaskan dan menentukan ukuran sudut pada bangun datar dalam satuan baku dengan menggunakan busur derajat dan 4.12 Mengukur sudut pada bangun datar dalam satuan baku dengan menggunakan busur derajat. Muatan ini dikemas dalam cerita yang mengandung keterampilan pemecahan masalah yang dikemukakan oleh Polya. Langkah-langkah dalam memecahkan masalah menurut Polya (1973:5) terdiri dari empat langkah, yaitu understanding the problem, devising a plan, carrying out the plan, dan looking back (Billstein et al., 2000) dan (Wahyudi \& Anugraheni, 2017).

Untuk mendukung tampilan dari MathLite, penelitian ini menggunakan teori media. Dalam (Molenda et al., 2002), media dalam Bahasa Inggris merupakan bentuk jamak dari "medium". Medium merupakan bahasa Latin yang artinya "diantara" atau "between". Media adalah apapun yang membawa informasi dari antara sumber dan penerima. Buku merupakan salah satu printed material dimana memiliki kegunaan seperti ketersediaannya dala berbagai topik dalam berbagai format. Buku juga fleksibel dan portabel untuk dibawa kemanapun dan tidak memerlukan alat khusus untuk menggunakannya. Dibanding media lain, media cetak harganya lebih terjangkau. Selain itu, media cetak juga memiliki keterbatasan yang berhubungan dengan pembacanya seperti tingkat membaca, kosa kata, pengetahuan awal, membutuhkan kemampuan mengingat, merupakan media yang satu arah, dan pemilihan buku biasanya ditentukan oleh kurikulum. Media cetak yang baik dalam hal ini adalah buku anak, perlu mempertimbangkan beberapa hal seperti gambar, warna, tata letak, jenis huruf, jenis kertas, kerapian penjilidan, pemilihan bahan tambahan, dan keawetannya saat dimanipulasi oleh siswa.

Pengembangan buku MathLite ini relevan dengan penelitian (Setiawan, 2018) dalam mengembangkan buku MathLite Seri Getuk ceria dengan hasil uji efektivitas menunjukkan bahwa MathLite secara signifikan mampu meningkatkan motivasi $(\mathrm{p}=0,000)$ dan minat siswa $(\mathrm{p}=0,003)$ terhadap matematika tetapi belum signifikan menurunkan kecemasan matematika siswa $(\mathrm{p}=0,575)$. Kemudian hasil penelitian(Sawen \& Setiawan, 2020) yaitu MathLite seri Siswa Teladan dinilai sangat baik dalam meningkatkan minat matematika siswa SD kelas 4 dengan perolehan skor rata-rata 3,3 dari nilai rata-rata maximal 4.

Sastra anak dalam bentuk komik juga dapat meningkatkan kemampuan pemecahan masalah matematika seperti dalam penelitian (Gumilang et al., 2019) bahwa media komik dengan model problem posing dapat meningkatkan kemampuan pemecahan masalah matematika dan (Pamungkas et al., 2019) yang media 
3523 Pengembangan Mathlite untuk Meningkatkan Kemampuan Pemecahan Masalah Matematika di Sekolah Dasar - Yohana Setiawan, Aprilina Isabela Maharani

DOI: https://doi.org/10.31004/basicedu.v5i5.1375

komiknya valid berdasarkan uji pakar media, pakar materi dan pakar pembelajaran serta dinyatakan efektif untuk meningkatkan pemecahan masalah dengan pendekatan saintifik.

MathLite yang dilengkapi dengan kegiatan mengukur sudut ini juga senada dengan penelitian (Narayani, 2019)yaitu pendekatan matematika realistik berbasis pemecahan masalah berbantuan media konkret dapat meningkatkan hasil belajar siswa. Selain itu, penelitian (Oktaviana et al., 2020) menunjukkan bahwa media Pop-Up Book berbasis Contextual Teaching and Learning dapat menfasilitasi pencapaian kemampuan pemecahan masalah siswa SMP.

Pada penelitian ini, dirumuskan dua masalah yaitu, 1) bagaimanakah mengembangkan buku MathLite yang layak untuk meningkatkan kemampuan pemecahan masalah matematika SD dan 2) seberapa layakkah Pengembangan Mathlite untuk meningkatkan kemampuan pemecahan masalah matematika SD. Dengan demikian, tujuan pengembangan pada penelitian ini adalah: 1) untuk mengembangkan langkah-langkah penyusunan MathLite untuk meningkatkan kemampuan pemecahan masalah matematika SD dan 2) untuk mengetahui tingkat kelayakan pengembangan mathlite untuk meningkatkan kemampuan pemecahan masalah matematika SD.

\section{METODE PENELITIAN}

Penelitian ini menggunakan model Research and Development $(\mathrm{R} \& \mathrm{D})$ yang dikembangkan oleh (Borg \& Gall, 1983). Berdasarkan model pengembangan (Borg \& Gall, 1983) maka prosedur pengembangan buku MathLite menggunakan tiga tahap dari sepuluh tahap pengembangan yaitu penelitian dan studi pendahuluan (research and information collecting), perencanaan penelitian (planning), pengembangan produk awal (develop preliminary form of product).

Teknik pengumpulan data kuantitatif untuk uji kelayakan yang digunakan dalam penelitian dan pengembangan MathLite terdiri dari teknik non tes yaitu kuesioner dengan empat skala (ratting scale) yang telah melalui tahap validasi isi.

Teknik analisis yang digunakan adalah teknik analisis deskriptif. Uji kelayakan media dalam uji validasi menggunakan teknik deskriptif presentase dan kategoris guna mengembangkan kelayakan media Mathlite: Seri Kerajaan Tudus. Mula-mula skor tersebut dipresentase dengan menggunakan rumus pada gambar 1.

$$
A P=\frac{\text { Skor Aktual }}{\text { Skor Ideal }} \times 100 \%
$$

Gambar 1. Rumus Persentase Skor

Keterangan Gambar 1:

AP

$$
\text { : Angka Presentase }
$$

Skor Aktual : Skor yang diberikan oleh validator ahli

Skor Ideal : Skor maksimal hasil kali antara jumlah item dengan skor maksimal masing-masing item

Angka presentase tersebut selanjutnya dikelompokkan menajdi lima kategori yang dikemukakan oleh Mawardi (2014) pada tabel 1.

Tabel 1. Interval dan Kategori Mawardi (2014)

\begin{tabular}{ll}
\hline \multicolumn{1}{c}{ Interval } & \multicolumn{1}{c}{ Kategori } \\
\hline $81-100 \%$ & Sangat tinggi \\
\hline $61-80 \%$ & Tinggi \\
\hline $41-60 \%$ & Cukup \\
\hline
\end{tabular}


3524 Pengembangan Mathlite untuk Meningkatkan Kemampuan Pemecahan Masalah Matematika di Sekolah Dasar - Yohana Setiawan, Aprilina Isabela Maharani

DOI: https://doi.org/10.31004/basicedu.v5i5.1375

\begin{tabular}{ll}
\hline $21-40 \%$ & Rendah \\
\hline $1-20 \%$ & Sangat rendah \\
\hline
\end{tabular}

\section{HASIL DAN PEMBAHASAN}

Dalam mengembangkan MathLite, penelitian ini menggunakan model Research and Development (R\&D) yang dikembangkan oleh (Borg \& Gall, 1983). Dalam penelitian ini hanya dilakukan tiga dari sepuluh tahap tersebut yaitu, (1) penelitian dan studi pendahuluan (research and information collecting), (2) perencanaan penelitian (planning), dan (3) pengembangan produk awal (develop preliminary form of product).

Pada tahap penelitian dan studi pendahuluan, dilakukan studi literatur kemudian dilakukan juga analisis kebutuhan yang berkaitan dengan permasalahan yang diangkat dalam penelitian. Pada tahap ini peneliti juga menuliskan kerangka kerja penelitian. Adapun kajian literatur yang dilakukan untuk mendukung penelitian adalah Gerakan Literasi Sekolah, Permendikbud, teori sastra anak, teori matematika untuk SD dan memperdalam materi penggunaan busur derajat di SD, serta mendalami teori pemecahan masalah khususnya pemecahan masalah Polya.

Dari hasil kajian litereatur, ditemukan bahwa ada contoh buku sastra matematika dari negara asing seperti Alexander, Who is Used to Be Rich Last Sunday, Amanda Beans Amazing Dream, Anno's Magic Seeds dan lainnya (Hunsander, 2004), The king's chessboard karya Birch, P., One grain of rice; A mathematical folktale karya Demi, Beanstalk: The measure of a giant karya Mc. Callum, dan lainya (Cox, 2012).

Analisis kebutuhan dilakukan di tiga sekolah secara random di Kabupaten Demak yaitu SDN Kebonagung, SDN Tlogosih 2, dan di SDN Sarimulyo 2. Penelitian presurvey ini dilakukan di perpustakaan sekolah dengan teknik angket dan melibatkan guru SD kelas IV yang dilakukan dengan teknik wawancara. Hasilnya, jumlah buku bermuatan matematika kelas 4 dibandingkan dengan jumlah keseluruhan buku di perpustakaan SDN Kebonagung 1 adalah 1,3\%, di SDN Tlogosih 2 adalah 1,8\%, dan di SDN Sarimulyo 2 adalah $2,9 \%$. Dari hasil wawancara, tidak banyak buku sastra anak yang mengandung materi matematika yang banyak ditemui adalah buku cerita yang bermuatan materi bahasa Indonesia, IPA, IPS, PPKN dan Agama. Di sekolah biasanya siswa hanya mengerjakan soal dengan jawaban yang benar tanpa disertai bagaimana prosesnya, sehingga sulit menentukan keberadaan buku yang mendukung kemampuan pemecahan masalah. Peneliti juga membawa draft MathLite sebagai buku yang dimaksudkan karena terkadang persepsi orang terhadap buku sastra yang mengandung matematika tidak sama seperti yang dimakasudkan peneliti. Setelah draft tersebut ditunjukkan ada antusias dari guru guru kelas IV tersebut yang ditunjukkan dengan argument mereka bahwa buku seperti itu tidak banyak ditemui. Hal ini senada dengan presurvey yang dilakukan (Setiawan, 2018) bahwa hanya mendapati kamus rumus matematika dan soal olimpiade matematika di toko buku, namun sastra matematika tidak ditemukan oleh penjual buku. Kerangka kerja penelitian dapat dilihat pada gambar 2 . 
3525 Pengembangan Mathlite untuk Meningkatkan Kemampuan Pemecahan Masalah Matematika di Sekolah Dasar - Yohana Setiawan, Aprilina Isabela Maharani

DOI: https://doi.org/10.31004/basicedu.v5i5.1375

\section{Studi Literatur}

GLS

Permedikbud (pembiasaaan membaca, Standar Proses,

Teori (Sastra anak, media, dan muatan matematika SD (busur derajat)

Pentingnya kemampuan Pemecahan Masalah

\section{Prasurvey lapangan:}

SD di Kabupaten Demak (3 random sampling) Standar isi)

Draft Buku (berdasarkan):

Konsep Sastra Anak

Konsep Media cetak (buku)

Bermuatan konsep Matematika

Mengandung Pemecahan

masalah (Polya)

\section{1}

Simpulan sementara:

Buku MathLite dibutuhkan

(untuk GLS dan meningkatkan

kemampuan Pemecahan masalah)

1

\section{Instrumen yang disiapkan:}

Prasurvey - Angket

Penelitian - Instrumen untuk ahli Sastra Anak, Ahli Media, Ahli

Matematika SD

Gambar 2. Kerangka Penelitian

Pada langkah kedua yaitu perencanaan penelitian disusun tujuan penelitian dan perkiraan dana, tenaga, dan waktu. Tenaga yang dimaksud adalah pihak-pihak yang akan dilibatkan dalam proses pembuatan seperti menentukan visual artist, percetakan, dan yang menentukan ahli dalam menilai kelayakan MathLite. Adapun tujuan penelitian ini difokuskan untuk mengembangkan MathLite berdasarkan teori sastra anak, media, dan matematika SD yang disusun berdasarkan teori pemecahan masalah Polya. Proses pembuatan ilustrasi dan layout dilakukan oleh Pendekar Visual (Instagram: @ pendekarvisual). Ahli yang terlibat dalam penelitian ini Eunice Widyanti S., S.Pd., M.Pd. sebagai Ahli Sastra Anak, Elvira Hoesein Radia, S.Pd., S.Mus., M.Pd. sebagai Ahli Media, dan Indri Anugraheni, S.Pd., M.Pd. sebagai Ahli Matematika SD.

Pada langkah pengembangan produk awal peneliti melakukan desain buku MathLite, mencetak dan melakukan uji kelayakan pada ahli media, ahli sastra anak, dan pada ahli matematika SD. Draft yang sudah disusun untuk presurvey dilakukan finalisasi dengan menambahkan ilustrasi dan layout oleh visual artist (lihat gambar 3).

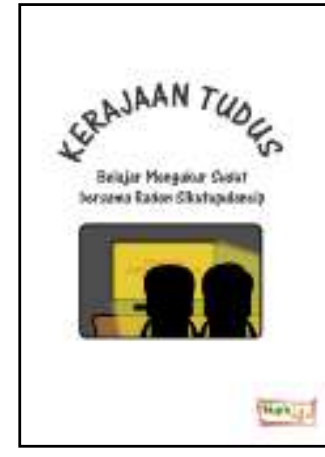

Gambar 3a. Draft

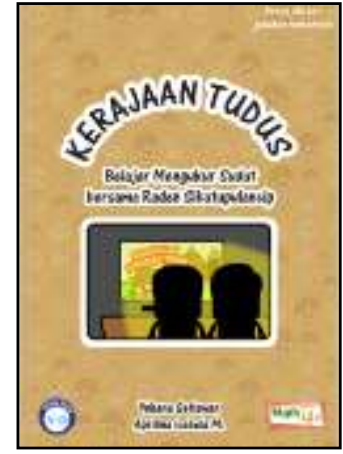

Gambar 3b. Editing 1

Gambar 3. Cover depan MathLite sebelum dan sesudah editing

Uji kelayakan dilakukan kepada tiga ahli. MathLite dilihat dari sudut pandang ahli sastra anak, matematika, dan media cetak yang juga akan dilihat dari kelayakannya dalam pemecahan masalah matematika SD. Dari sudut pandag sastra anak, dalam hal ini bergenre fiksi resalistis, MathLite harus memiliki plot, character, setting, theme, style, emotional impact, imaginative impact, vision of the author, dan realistic 
3526 Pengembangan Mathlite untuk Meningkatkan Kemampuan Pemecahan Masalah Matematika di Sekolah Dasar - Yohana Setiawan, Aprilina Isabela Maharani

DOI: https://doi.org/10.31004/basicedu.v5i5.1375

element. Kandungan konsep geometri dapat dilihat dari K-13 yaitu kompetensi dasar kelas IV SD 3.12 Menjelaskan dan menentukan ukuran sudut pada bangun datar dalam satuan baku dengan menggunakan busur derajat dan 4.12 Mengukur sudut pada bangun datar dalam satuan baku dengan menggunakan busur derajat. Dari sisi media cetak akan dinilai kelayakannya berdasarkan konsistensi, format, organisasi, daya tarik, ukuran huruf, penggunaan spasi, ilustrasinya atau gambar, warna, tata letak, jenis huruf, jenis kertas, kerapian penjilidan, pemilihan bahan tambahan, dan keawetannya saat dimanipulasi oleh siswa. Hasil validasi dapat dilihat pada tabel 2 .

Tabel 2. Validasi Mathlite seri Kerajaan Tudus Ahli Materi, Media, Sastra anak

\begin{tabular}{|c|c|c|c|}
\hline Ahli & Aspek & Persentase & Kriteria \\
\hline \multirow{3}{*}{ Materi } & $\begin{array}{l}\text { Membaca alat ukur sudut dalam satuan } \\
\text { baku berupa busur derajat }\end{array}$ & \multirow{3}{*}{$75 \%$} & \multirow{3}{*}{ Tinggi } \\
\hline & Menulis lambang sudut dalam satuan baku & & \\
\hline & $\begin{array}{l}\text { Menentukan ukuran sudut dua garis dengan } \\
\text { busur derajat }\end{array}$ & & \\
\hline \multirow[t]{2}{*}{ Media } & $\begin{array}{l}\text { Komponen Visual Alignment, } \\
\text { Keseimbangan, Warna, Karakter, Jarak, } \\
\text { Kontras Background }\end{array}$ & \multirow[t]{2}{*}{$71 \%$} & \multirow[t]{2}{*}{ Tinggi } \\
\hline & Komponen Verbal & & \\
\hline Sastra Anak & Unsur - unsur Cerita & $75 \%$ & Tinggi \\
\hline
\end{tabular}

Mathlite seri Kerajaan Tudus berdasarkan penilaian ahli Materi memiliki nilai persentase sebesar $75 \%$ yang artinya bahwa penilaian validasi Mathlite seri Kerajaan Tudus Ahli Materi termasuk dalam kriteria tinggi. Hal tersebut berarti bahwa seri Kerajaan Tudus dapat digunakan untuk membaca alat ukur sudut dalam satuan baku berupa busur derajat; menulis lambang sudut dalam satuan baku, dan menentukan ukuran sudut dua garis dengan busur derajat. Nilai persentase dari validator Media adalah sebesar $71 \%$. Hal ini berarti bahwa komponen visual alignment, keseimbangan, warna, karakter, jarak, kontras background MathLite sudah termasuk kedalam kriteria tinggi. Ahli sastra anak memberikan nilai dengan persentase $75 \%$ yang artinya bahwa validasi Mathlite seri Kerajaan Tudus oleh ahli Sastra Anak berdasarkan unsur-unsur cerita termasuk dalam kriteria tinggi.

Ditinjau dari variabel kemampuan pemecahan masalah menurut Polya, dengan aspek understanding the problem, devising a plan, carrying out the plan, dan looking back, Skor persentase rata-rata dari ke tiga ahli adalah 85,6\% sehingga termasuk dalam kategori Sangat Tinggi. Menurut Ahli Materi dan Sastra Anak, Buku MathLite berada pada kriteria Sangat Tinggi dalam perannya meningkatkan kemampuan pemecahan masalah. Dengan rata-rata persentase $75 \%$, Ahli Media menilai bahwa peran MathLite dalam meningkatkan kemampuan pemecahan masalah termasuk dalam kriteria Tinggi.

\begin{tabular}{|c|c|c|c|c|c|c|c|c|}
\hline \multirow{2}{*}{$\begin{array}{c}\text { Kemampuan } \\
\text { Pemecahan } \\
\text { Masalah menurut } \\
\text { Polya dalam } \\
\text { MathLite }\end{array}$} & \multicolumn{2}{|c|}{ Ahli Materi } & \multicolumn{2}{|c|}{ Ahli Media } & \multicolumn{2}{|c|}{$\begin{array}{c}\text { Ahli Sastra } \\
\text { Anak }\end{array}$} & \multicolumn{2}{|c|}{$\begin{array}{c}\text { Rata-Rata } \\
\text { (ketiga ahli) }\end{array}$} \\
\hline & $(\%)$ & Kriteria & $(\%)$ & Kriteria & $(\%)$ & Kriteria & $(\%)$ & Kriteria \\
\hline $\begin{array}{l}\text { Understanding the } \\
\text { problem }\end{array}$ & 75 & Tinggi & 75 & Tinggi & 100 & $\begin{array}{l}\text { Sangat } \\
\text { Tinggi }\end{array}$ & 83,3 & $\begin{array}{l}\text { Sangat } \\
\text { Tinggi }\end{array}$ \\
\hline Devising a plan & 100 & $\begin{array}{l}\text { Sangat } \\
\text { Tinggi }\end{array}$ & 75 & Tinggi & 91.6 & $\begin{array}{l}\text { Sangat } \\
\text { Tinggi }\end{array}$ & 88,9 & $\begin{array}{l}\text { Sangat } \\
\text { Tinggi }\end{array}$ \\
\hline Carrying out the & 75 & Tinggi & 75 & Tinggi & 100 & Sangat & 83,3 & Sangat \\
\hline
\end{tabular}


3527 Pengembangan Mathlite untuk Meningkatkan Kemampuan Pemecahan Masalah Matematika di Sekolah Dasar - Yohana Setiawan, Aprilina Isabela Maharani

DOI: https://doi.org/10.31004/basicedu.v5i5.1375

\begin{tabular}{lcccccccc}
\hline plan & & & & & Tinggi & Tinggi \\
\hline Looking Back & 100 & $\begin{array}{l}\text { Sangat } \\
\text { Tinggi }\end{array}$ & 75 & Tinggi & 83 & $\begin{array}{c}\text { Sangat } \\
\text { Tinggi }\end{array}$ & 86 & $\begin{array}{l}\text { Sangat } \\
\text { Tinggi }\end{array}$ \\
\hline Skor Rata rata & 87,5 & $\begin{array}{l}\text { Sangat } \\
\text { tinggi }\end{array}$ & 75 & Tinggi & 94,3 & $\begin{array}{c}\text { Sangat } \\
\text { Tinggi }\end{array}$ & 85,6 & $\begin{array}{l}\text { Sangat } \\
\text { Tinggi }\end{array}$ \\
\hline $\begin{array}{l}\text { Skor Rata rata dari } \\
\text { ke-3 ahli }\end{array}$ & & & $85,6=$ Kriteria Sangat Tinggi & & \\
\hline
\end{tabular}

Pada tabel 3, Ahli Materi memberikan penilaian pada aspek understanding the problem sebesar 75\%, aspek devising a plan dengan persentase sebesar $100 \%$, carrying out the plan sebesar $75 \%$, dan looking back sebesar $100 \%$. Ahli Sastra Anak memberikan nilai persentase pada aspek understanding the problem sebesar $100 \%$, aspek devising a plan dengan persentase sebesar 91,6\%, carrying out the plan sebesar 100\%, dan looking back sebesar $83 \%$. Ahli Media memberikan nilai sebesar $75 \%$ pada semua aspek pemecahan masalah.

Adapun saran yang diberikan oleh peneliti berdasarkan hasil validasi oleh Ahli Materi, Media, dan Sastra Anak menunjukkan bahwa MathLite seri Kerajaan Tudus layak digunakan untuk meningkatkan kemampuan pemecahan masalah matematika.

Ditinjau dari penilaian ketiga ahli berdasarkan teori Polya (Billstein et al., 2000) dan (Wahyudi \& Anugraheni, 2017) peran MathLite dalam meningkatkan pemecahan masalah matematika SD dari aspek understanding the problem termasuk dalam kriteria sangat tinggi yaitu sebesar $83.3 \%$. Hal ini dikarenakan MathLite memiliki masalah masalah yang berkaitan dengan matematika dalam dunia anak. Buku MathLite seri kerajaan tudus membuat siswa dapat menemukan permasalahan yang berkaitan dengan pengukuran sudut dengan busur derajat dan siswa diharapkan dapat menganalisis kondisi yang berkaitan dengan pengukuran sudut dengan busur derajat. Selain itu, buku MathLite seri kerajaan tudus membuat siswa dapat menghubungkan masalah dalam cerita ke dalam dunia anak dalam menggunakan bujur derajat. (Amir, 2014) berpendapat bahwa siswa dapat belajar memecahkan masalah dengan media manipulative dalam hal ini MathLite yang dilengkapi alat bantu busur derajat yang dapat di gunakan dalam "halaman percobaan". Siswa tidak hanya membaca tetapi juga melakukan interaksi dengan buku.

Pada aspek devising a plan, MathLite mendapat persentase sebesar 88,9\% dan termasuk dalam kriteria Sangat Tinggi. Buku MathLite seri kerajaan tudus membuat siswa dapat memikirkan cara penyelesaian masalah yang berkaitan dengan pengukuran sudut dengan busur derajat dan membantu siswa untuk menaksir (memperkirakan) besaran sudut. Buku MathLite seri kerajaan tudus ini memberi salah satu cara pada siswa untuk menyelesaikan masalah pengukuran sudut dengan busur (lihat gambar 4).

Kriteria Sangat Tinggi juga diberikan oleh ketiga ahli pada aspek carrying out the plan. Buku MathLite seri kerajaan tudus ini membantu siswa menggunakan busur dalam mengukur sudut dengan mengimplementasikan langkah-langkah penggunaan busur. Selain itu, MathLite seri kerajaan tudus ini dapat membantu siswa menggunakan simbol simbol sudut sehingga siswa dapat membaca sudut. 
3528 Pengembangan Mathlite untuk Meningkatkan Kemampuan Pemecahan Masalah Matematika di Sekolah Dasar - Yohana Setiawan, Aprilina Isabela Maharani

DOI: https://doi.org/10.31004/basicedu.v5i5.1375

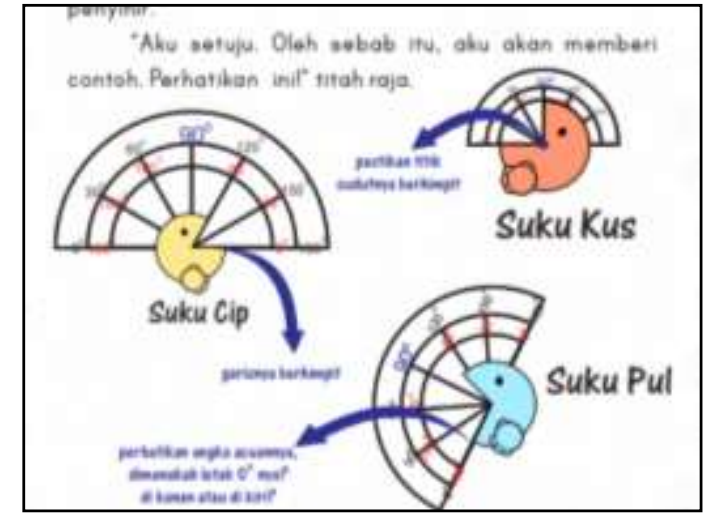

Gambar 4a.

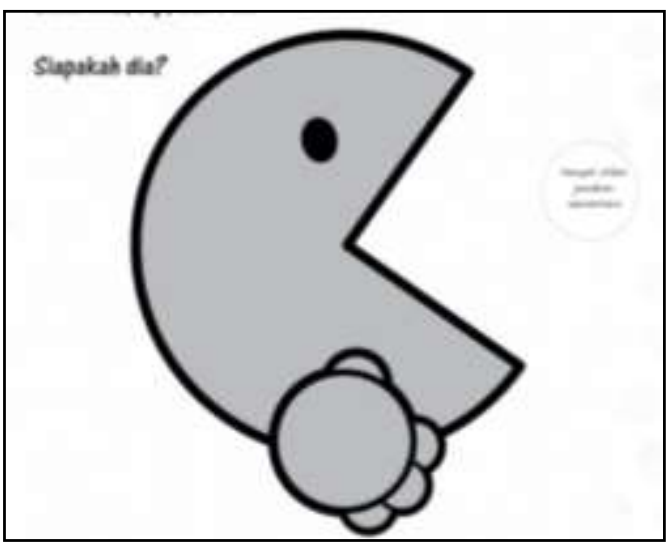

Gambar 4b.

Gambar 4. Salah satu cara menentukan jenis sudut adalah dengan menggunakan busur derajat (4a), alternatif lain dapat menggunakan perkiraan, kreativitas siswa dipersilakan misalnya menggunakan sudut buku, meja dll (4b) dilengkapi dengan sticker jawaban sementara.

Buku MathLite seri kerajaan tudus membantu siswa melakukan pengecekan ulang terhadap jawaban siswa dan mendampingi siswa menarik kesimpulan/jawaban. Buku MathLite ini juga membuka kesempatan untuk siswa merespons argumen/jawaban yang berbeda sehingga, pada aspek Looking Back, para ahli memberikan nilai persentase sebesar $86 \%$ atau termasuk dalam kriteria Sangat Tinggi. MathLite juga dilengkapi dengan kunci jawaban yang bisa membuat siswa mengalami proses look back karena siswa diminta untuk menempelkan sticker jawaban sementara pada halaman percobaan (lihat gambar 5).

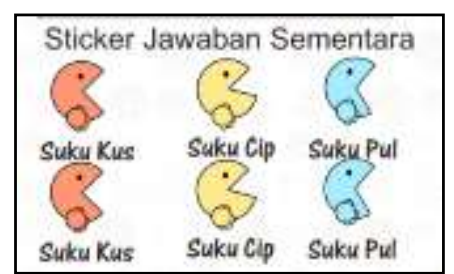

5a. Sticker

(ada di halaman bonus)

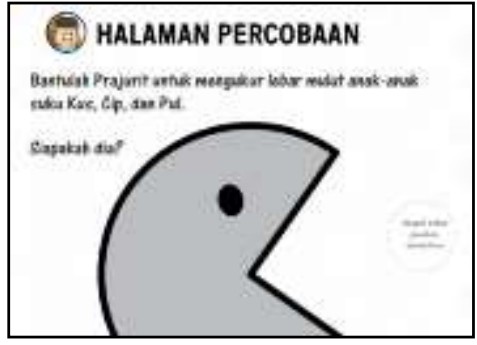

5b. Halaman Percobaan (ada tempat untuk menempel sticker)

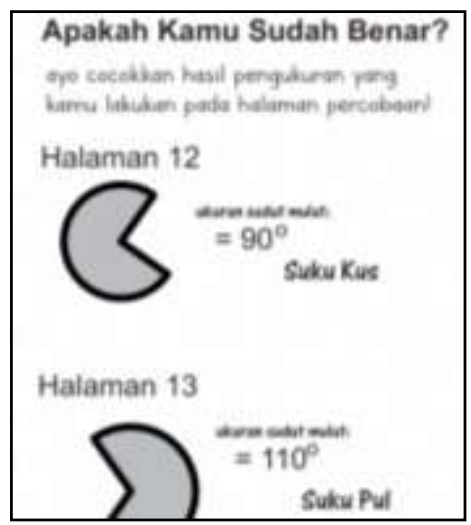

5c. Kunci jawaban

Gambar 5. Sticker, Halaman percobaan, dan kunci jawaban

\section{KESIMPULAN}

Hasil validasi oleh Ahli Materi, Media, dan Sastra Anak menunjukkan bahwa MathLite seri Kerajaan Tudus layak digunakan untuk meningkatkan kemampuan pemecahan masalah matematika. Namun efektifitas dari buku ini belum teruji, sehingga peneliti menyarankan untuk dilakukannya penelitian lanjut khususnya kepada subjek penelitian yaitu siswa kelas IV SD. 
3529 Pengembangan Mathlite untuk Meningkatkan Kemampuan Pemecahan Masalah Matematika di Sekolah Dasar - Yohana Setiawan, Aprilina Isabela Maharani

DOI: https://doi.org/10.31004/basicedu.v5i5.1375

\section{UCAPAN TERIMA KASIH}

Peneliti sekaligus penulis mengucapkan puji syukur kepada Tuhan Yang Maha Esa untuk setiap hikmat dan berkat yang diberikan dan terimakasih banyak kepada seluruh dosen pembimbing, keluarga, dan juga teman-teman yang telah mendukung dan memberikan semangat selama proses penelitian ini berlangsung.

\section{DAFTAR PUSTAKA}

Alhaddar, G., \& Afdal, A. (2019). Peningkatan Minat Baca Anak Melalui Sosialiasi Pentingnya Membaca Dan Media Keranjang Buku Di Kampung Cerdas. Jurnal Abdimas Mahakam, 3(2), 109. Https://Doi.Org/10.24903/Jam.V3i2.499

Amir, A. (2014). Pembelajaran Matematika SD Dengan Menggunakan Media Manipulatif. Forum Paedagogik, 6.

Billstein, R., Libeskind, S., Lott, J. W., \& Boschmans, B. (2000). A Problem-Solving Approach To Mathematic: For Elementary School Teachers. Boston: Pearson.

Borg, W. R., \& Gall, M. D. (1983). Educational Research: An Intoduction.

Brown, Carol Lynch. (1999). Essentials Of Children's Literature (V. C. Lanigan \& B. Keane (Eds.)). Allyn And Bacon.

Http://Staffnew.Uny.Ac.Id/Upload/132299491/Pendidikan/Essentialsofchildrensliterature.Pdf

Burhan Nurgiantoro. (2018). Sastra Anak Pengantar Pemahaman Dunia Anak. Yogyakarta, Gadjah Mada University Press, 2013, 2.

Direktorat Jenderal Pendidikan Dasar, \& Kebudayaan, K. P. D. (2016). Desain Induk Gerakan Literasi Sekolah (P. . Pangesti Wiedarti, M.Appl.Ling. \& P. D. Kisyani-Laksono (Eds.)). Direktorat Jenderal Pendidikan Dasar Dan Menengah Kementerian Pendidikan Dan Kebudayaan.

Gumilang, M. R., Wahyudi, W., \& Indarini, E. (2019). Pengembangan Media Komik Dengan Model Problem Posing Untuk Meningkatkan Kemampuan Pemecahan Masalah Matematika. Journal Of Medives: Journal Of Mathematics Education IKIP Veteran Semarang, 3(2), 185. Https://Doi.Org/10.31331/Medivesveteran.V3i2.860

Ina V.S. Mullis, Michael O. Martin, P. F., \& Drucker, And K. T. (2012). PIRLS 2011 International Results In Reading (U. Chestnut Hill, MA (Ed.)).

Istiqlal, M. (2017). Pengembangan Multimedia Interaktif Dalam Pembelajaran Matematika. Jipmat, 2(1). Https://Doi.Org/10.26877/Jipmat.V2i1.1480

Mitchell, D. (2003). Children's Literature, An Invitation To The World. Boston : Ablongman.

Molenda, M., Russell, J. D., \& Smaldino, S. E. (2002). Instructional Media And Technologies For Learning 7th Edition (R. Heinich (Ed.)). Pearson College Div; 7th Edition (July 16, 2001).

Narayani, N. P. U. D. (2019). Pengaruh Pendekatan Matematika Realistik Berbasis Pemecahan Masalah Berbantuan Media Konkret Terhadap Hasil Belajar Matematika. Jurnal Ilmiah Sekolah Dasar, 3(2), 220. Https://Doi.Org/10.23887/Jisd.V3i2.17775

NCTM. (2000). Principles And Standar For School Mathematic. NCTM.

Oktaviana, D., Prihatin, I., \& Fahrizar, F. (2020). Pengembangan Media Pop-Up Book Berbasis Contextual Teaching And Learning Dalam Pencapaian Kemampuan Pemecahan Masalah Siswa Smp. AKSIOMA: Jurnal Program Studi Pendidikan Matematika, 9(1), 1. Https://Doi.Org/10.24127/Ajpm.V9i1.2543

Pamungkas, D., Wahyudi, W., \& Indarini, E. (2019). Pengembangan Media Komik Dengan Pendekatan Saintifik Untuk Meningkatkan Kemampuan Pemecahan Masalah Matematika Sd. JURNAL PAJAR (Pendidikan Dan Pengajaran), 3(6), 1405. Https://Doi.Org/10.33578/Pjr.V3i6.7904 
3530 Pengembangan Mathlite untuk Meningkatkan Kemampuan Pemecahan Masalah Matematika di Sekolah Dasar - Yohana Setiawan, Aprilina Isabela Maharani

DOI: https://doi.org/10.31004/basicedu.v5i5.1375

Sawen, J. D., \& Setiawan, Y. (2020). Pengembangan Buku Mathlite Seri Statistik Untuk Meningkatkan Minat Matematika Siswa Kelas 4 SD. Jurnal Pendidikan Tambusai, 4(2), 1164-1175.

Setiawan, Y. (2018). Pengembangan Buku Mathlite Dalam Meningkatkan Motivasi, Minat, Dan Menurunkan Kecemasan Matematika Siswa Kelas IV SD Sekecamatan Magelang Tengah. Eprints@UNY. Https://Eprints.Uny.Ac.Id/60787/

Setyaningsih, R. (2019). Proses Metakognisi Mahasiswa Dengan Tipe Adversity Quotient (Aq) Quitters Dalam Memecahkan Masalah Matematika. Satya Widya, 34(2), 112-124. Https://Doi.Org/10.24246/J.Sw.2018.V34.I2.P112-124

Wahyudi, \& Anugraheni, I. (2017). Strategi Pemecahan Masalah Matematika. In Satya Wacana University Press (Issue August). Https://Herryps.Files.Wordpress.Com/2010/09/Strategi-Pemecahan-MasalahMatematika.Pdf 